\title{
Weathering and Degradation Assessment of Rock Properties at the West Stone Pagoda, Gameunsaji Temple Site, Korea
}

\author{
Chan Hee Lee, Myeong Seong Lee ${ }^{\mathrm{b}, *}$ and Jiyoung Kim ${ }^{\mathrm{a}}$ \\ ${ }^{a}$ Department of Cultural Heritage Conservation Sciences, Kongju National University, Kongju 314-701, Korea \\ ${ }^{\mathrm{b}}$ Conservation Science Division, National Research Institute of Cultural Heritage, Daejeon 305-380, Korea
}

Manuscript received 10 October 2012; revised 31 October 2012; accepted 6 November 2012

(c) The Korean Society of Conservation Science for Cultural Heritage 2012

\begin{abstract}
The West Stone Pagoda at Gameunsaji Temple Site constructed in the 7th century is mainly composed of dark grey dacitic tuff bearing small numerous dioritic xenoliths. These xenoliths resulted in small holes due to differential weathering process from the host rocks. Physical strength of the pagoda was decreased due to weathering and damage caused by petrological, biological and coastal environmental factors. The southeastern part of the pagoda was extremely deteriorated that the rock surface showed exfoliation, fracture, open cavity, granular decomposition of minerals and salt crystallization by seawater spray from the eastern coast. The stone blocks were intersected by numerous cracks and contaminated by subsequent material such as cement mortar and iron plates. Also, the pagoda was colonized by algae, fungi, lichen and bryophytes on the roof rock surface and the gaps between the blocks. As a result of ultrasonic test, the rock materials fell under Highly Weathered Grade (HW) or Completely Weathered Grade (CW). Thus, conservational intervention is essentially required to prevent further weakening of the rock materials.
\end{abstract}

Key words: Dacitic tuff, Seawater spray, Contamination, Weathering, Deterioration, Ultrasonic velocity

\section{INTRODUCTION}

The three-story stone pagoda of the Gameunsaji temple site nominated as Korea National Treasure No. 112 in 1962 (Figure 1). The Gameunsaji temple stands on a northern hill to Daejong stream, which is along the coast of Gyeongju City located approximately $300 \mathrm{~km}$ southeast of Seoul in the Korean peninsula. The Unified Shilla Kingdom (AD 650 to 930) of ancient Korea left a stone heritage of many wonderful pagodas, stupas, temples and grottos, which proved just how sophisticated Shilla's artistic works. They declared of World Cultural Heritage by UNESCO in 1995. Many studies have been done on the stone assets from the perspectives of history, archaeology and art history.

However, there have been only a few studies on them in terms of rock compositions, structural stability, petrological weathering,

*Corresponding author: Myeong Seong Lee

E-mail: mslee75@korea.kr degradations and conservation measures. The fundamental cause of damage in stone is acid rain, when this is joined by climatic changes and reactions between water and rocks, whose weathering residuals accelerate the process of physicochemical degradation due to recrystallization and expanding volume. The open gaps on the rock surface provide a home to algae, bryophyte, lichen and other plants, which promote mechanical weathering even more as they grow. A comprehensive study on this phenomenon has been studied by Ashurst and Dimes (2001) and Lisci et al. (2003).

Organisms alter the surface environment of stone cultural assets, which is why outdoor stone cultural assets should be conservation treatments done before biological contamination takes over them. It is necessary to fill or reinforce the parts that are damaged by discontinuities, exfoliation and peel-off. Any restoration treatments should follow a clinical test considering the degree of weathering (Fidler, 2002). This study investigated the pagoda in terms of degradation assessment, lithological characteristics and conservation scheme for the future restoration program. The results were updated based on the previous study (Lee et al., 2004) by combining with ultrasonic velocity of the materials.

\section{CURRENT STATES AND METHODOLOGY}

\subsection{Current states}

The Gameunsa temple was constructed by King Munmu (AD 661 to 681) of the Unified Shilla Kingdom in ancient Korea, with the intention of defeating the Japanese pirates and protecting the country. The King Shinmun (AD 681 to 692) completed the temple in the second year of his reign. The three-story pagodas in the east and west must have been built around the same time (Jeong et al., 1999). Currently, the original main buildings in the temple are missing, only with the two pagodas left. They both stand 13.4 meters in height, being the tallest stone pagodas during the period of the Unified Shilla Kingdom. The two pagodas share 
almost every feature, using 12 face rock blocks in the same kind of the lower stylobate and foundation stones.

The upper stylobate consists of 12 face rocks and eights roof rocks. Between the materials of the stylobate, there are three pillars in the upper part and two pillars in the lower part. The uppermost pillar has left only the covered-square rock on top of the third roof stone. The top of the pagoda set up by an only an iron rod. The roof stones become narrower as they go up and stretch in a straight line to the seal engraving under the eaves. Under each of the roof stones, there are layers with a style that is reminiscent of a brick style pagoda. Still, the evident reserve feature in the seal engraving confirms the fact that the pagoda resembles a wooden structure in the roofs (CHA, 2012).

The five-layered pedestal of the roof stones and the water dropping parts that are slanted like a roof have also reproduced by the successors. Even the supporting style started its own long tradition with the two-layered angular support stones for the roof rocks of the lower stylobate. There is another two-layered support stone on top of the roof stones supporting the materials of the body layer right above (Figure 1B). It was in 1959 by the National Museum of Korea when the temple site excavated firstly. At that time, the stone pagoda was also dismantled and repaired. A rare sarira container was discovered in the third-floor body of the pagoda. This was displayed at the National Museum of Korea. The sarira container as well as the body has not undergone any kind of reinforcement or repair treatments, keeping their original shape and offering valuable information about the brick-style stone pagodas of the 7th century of Korea.

\subsection{Methodology}

Detailed investigation of physical and biological weathering features of the pagoda carried out in this study (Figure 1C). Four tiny rock fragments from a roof and the main body were sampled. The rocks were used for identification of composition, lithological and mineralogical information. Also, investigation and measurement of structural instability, crack damage status and exfoliated areas were done.

For chemical analysis, we used inductively coupled plasma spectrometer (ICP-OES, ICP-MS) and instrumental neutron activation analysis (INAA) for quantitative analysis. A polarizing microscope and scanning electron microscope (SEM) were also used to investigate qualitative mineral composition, relative contents, mineralogical relationships and textures deteriorated by weathering of the pagoda rocks used. SEM was ISI-SX-40 from Shimatzu that had an energy dispersive X-ray analyzer made by LINK.

Some of the samples were analyzed via X-ray powder diffraction. The XRD instrument was a D/Max-IIB from Rigaku, and the X-ray was at $\mathrm{CuK} \alpha$ with $30 \mathrm{kV}$ and $15 \mathrm{~mA}$. Relative mineral content and ratio calculated by a modal analysis with fragments from each sample. For modal composition, Leitz Co.'s automatic calculator-mounted Orthoplan (071948) microscope has used. Results from those analyses were evaluated by essential reliability measurements.

To measure the quantitative weathering degree through the estimation of the pagoda's strength, ultrasonic test, one of the nondestructive diagnostic methods, was conducted. The overall
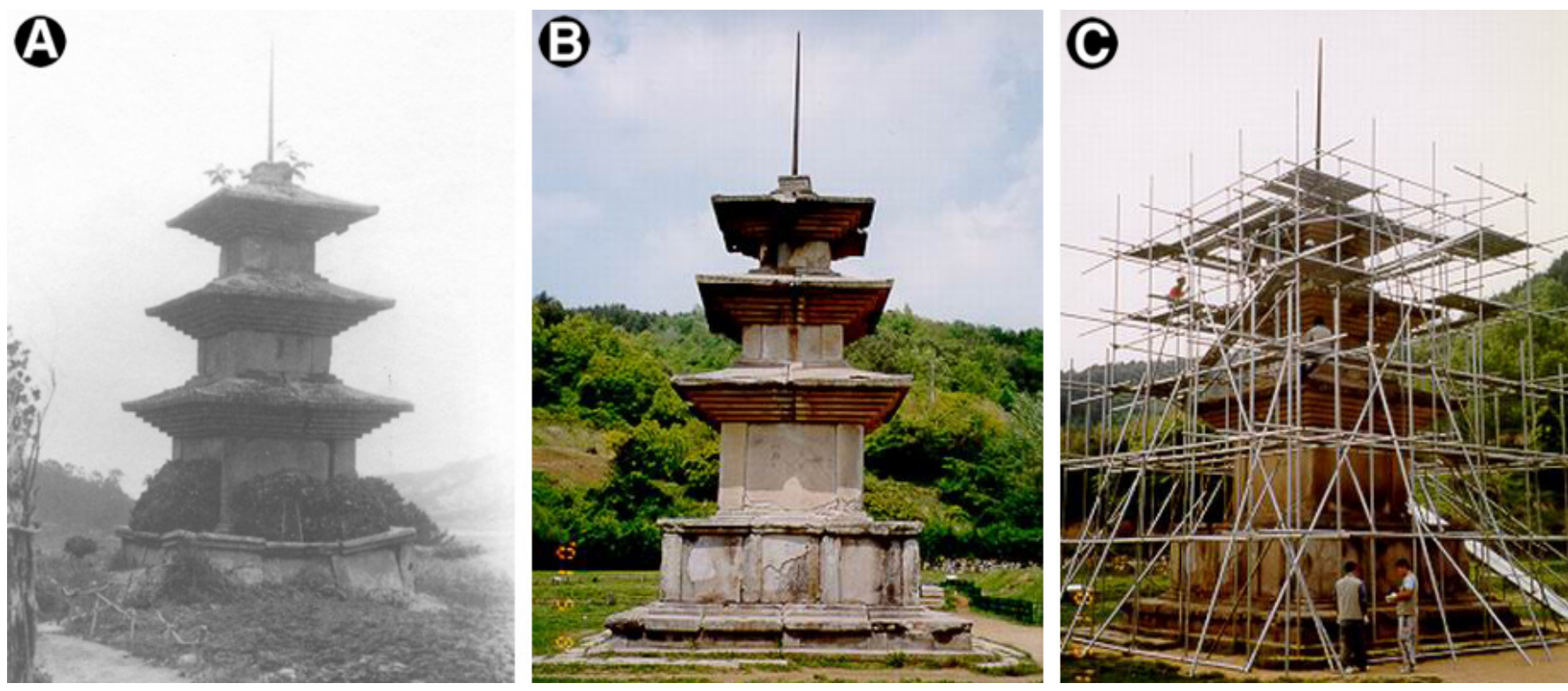

Figure 1. Field occurrences of stone pagoda in the Gameunsaji temple site. (A) Photograph in 1910s shows central subsidence of the pagoda. (B) This stone pagoda is intensively exfoliated on the surface of the stylobate properties. (C) Set-up of the scaffold by stainless steel pipe and plates for detail survey. 
weathering grade was identified by projecting this value to each elevation. Model PUNDIT-plus of CNS Farnell was applied as a device and Golden Software Surfer 8 was used for 2D contour modeling (Fitzner, 2004; Lee et al., 2011).

\section{LITHOLOGY AND MINERALOGY}

According to its composition, granitic rocks around the Gameunsaji temple site were classified into three kinds of rock types by Lee et al. (1995) ; biotite granodiorite, biotite granite and alkali granite. Biotite granodiorite is widely called granodiorite of mountain Toham near the Gameunsaji temple site. It is usually medium to coarse-grained and equigranualr texture. Rock forming minerals consist mainly of plagioclase, quartz, alkali feldspar, amphibole and biotite. Biotite granite is mainly medium-grained and usually equigranular texture, but it shows partly of porphyritic texture and show micrographic texture well. Alkali granite is usually called Namsan granite (Jwa et al., 2000). It is medium to coarse-grained and equigranular leucocratic granite.

Rock chips for analysis were collected from the roof and body of the pagoda in order to use them in inspecting the materials. The rocks seem to be hard to identify based on the information of petrography, chemistry and rock-forming minerals. Considering all the petrological features, the rocks of the pagoda consists of
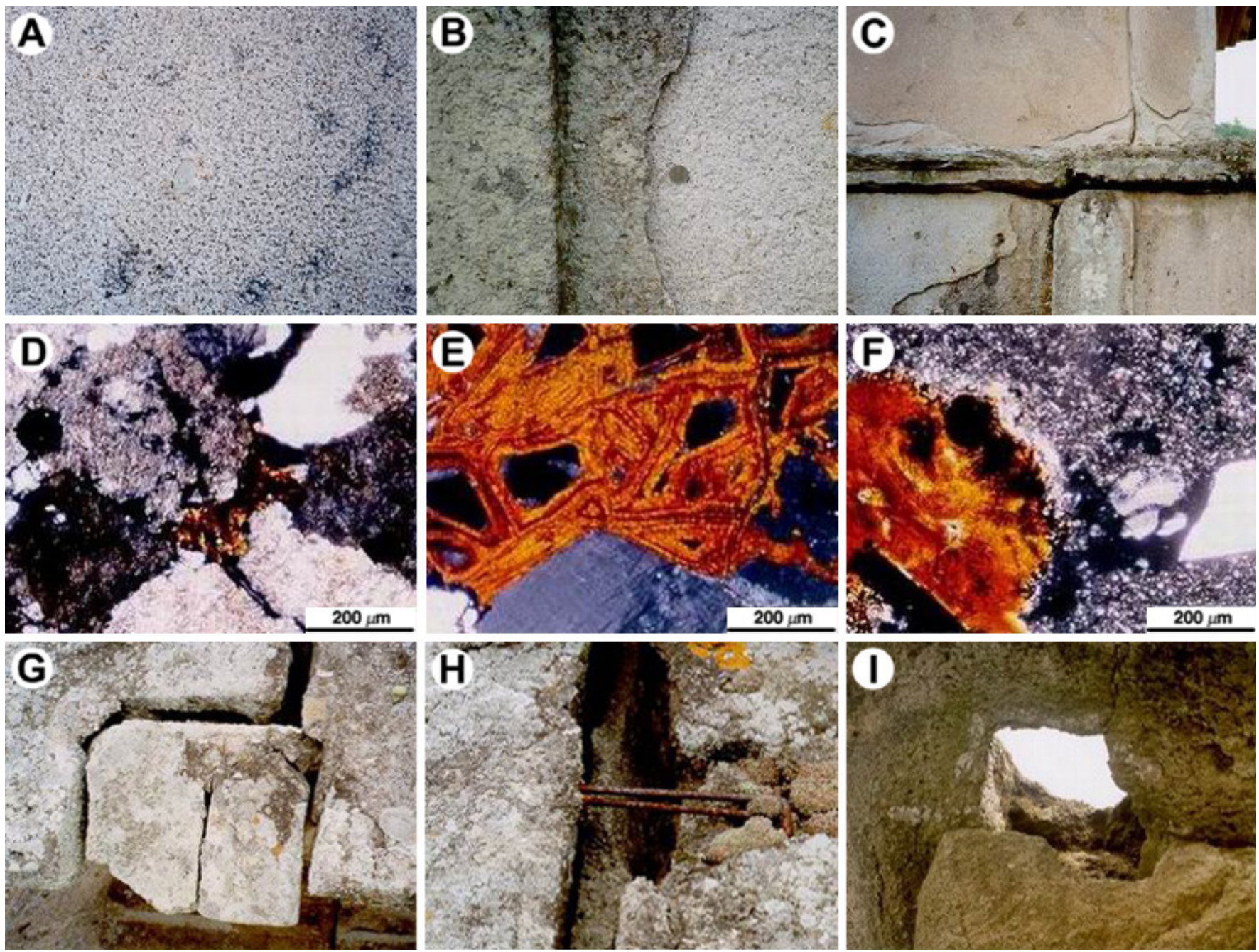

Figure 2. Rock properties and microphotographs showing the stone pagoda. (A) Face rocks of dioritic xenolith-bearing dacitic tuff at the basement. (B) Sheet-like exfoliation and dislocation of the surface showing the basement rock. (C) Main body of basement rocks inserting concrete occurred with highly deterioration states. (D) Micrographic texture composed of quartz and alkali feldspar which show highly clay mineralization. (E) Amorphous colloidal iron hydroxides in the cavity of rock forming minerals. (F) Secondary clay minerals occurred along the twin plane of plagioclase and biotite in the diorite xenolith. $(\mathrm{G})$ Extensively fractured roof rock of the 3rd floor. (H) Wide gap between the each block of the 3rd floor roof stone are bolted iron wires. (I) Large open hole because of differential weathering between host rock and basic xenolith. 
dacitic tuff containing dioritic xenolith in part, which is similar to the sub-volcanic rocks of the Beomgokri Formation near the
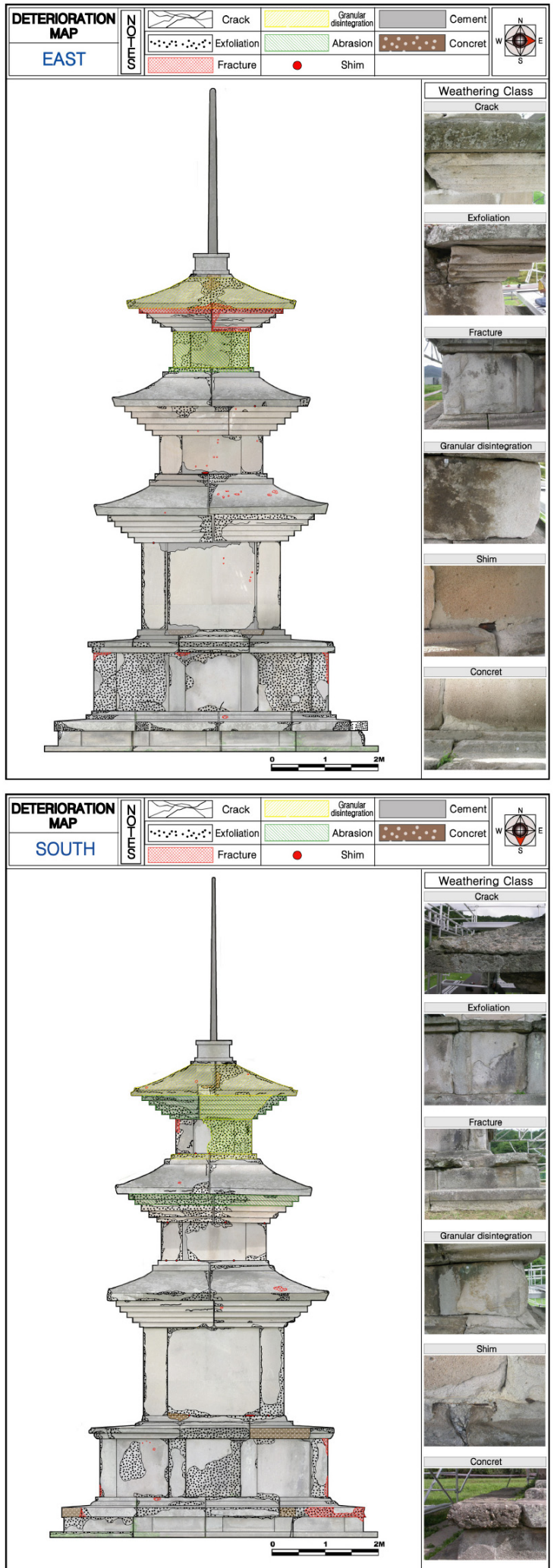

mountain Toham (Figure 2).

The surface color of the rocks is light grey in general and partly
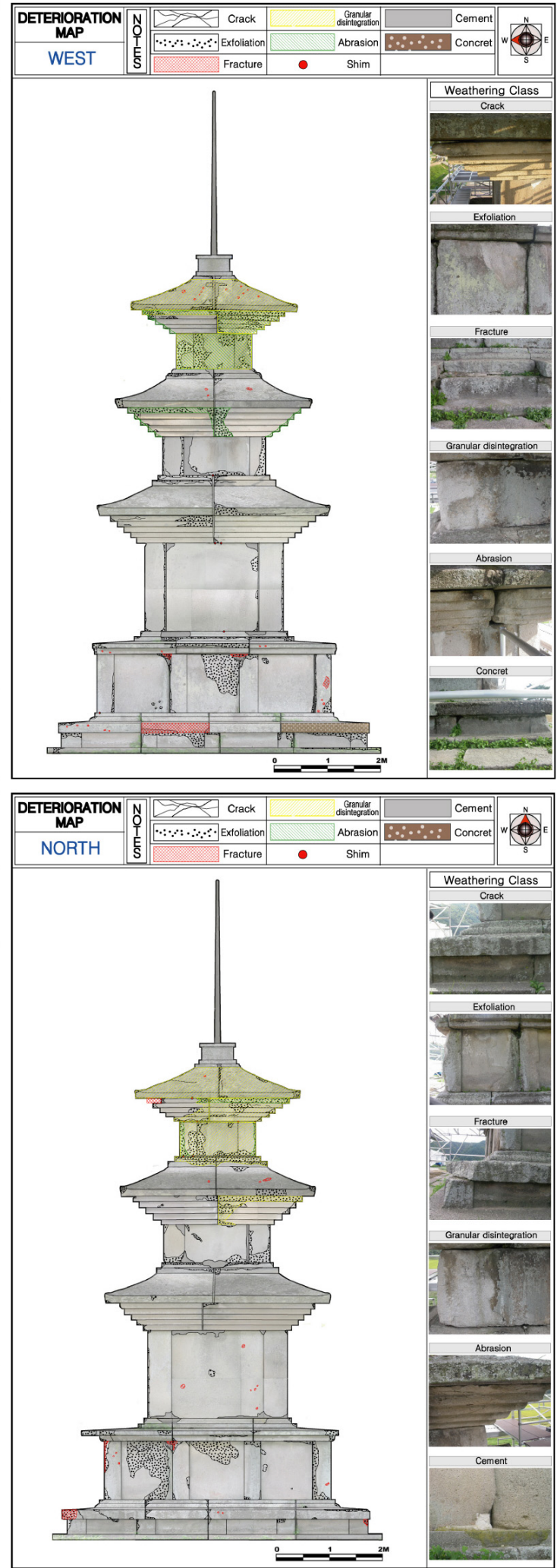

Figure 3. Detailed deterioration maps on the eastern, western, southern and northern part of stone pagoda. 
grayish yellow having big and small dioritic xenolith (Figure $2 \mathrm{~A})$. Most surfaces of the rock face were strong exfoliations. We can see the medium-grained granular texture along the homogeneous lump of biotite, quartz and plagioclase (Figure 2B). There are two kinds of open gaps, one of which is primary and the other secondary, formed from partial decomposition of quartz particles due to weathering (Figure 2C). The former are bigger and more irregular in shape, and have rather sharp edges in parts, while the latter are about the same size as quartz and mostly rounded in shape.

Those rock crusts fell from the pagoda because of serious degradation. Rock-forming minerals of the pagoda stone were usually quartz, plagioclase and biotite with small amounts of orthoclase, microcline, muscovite, opaque minerals and epidote. Quartz shows anhedral to subhedral habits, while the plagioclase are subhedral or euhedral (Figure 2D). In Figure 2E, there are amorphous hydroxides of colloform texture filled in between the intergranular space of the rock-forming minerals. Biotite was in sheets and altered into sericite or chlorite even through the cleavage of the grains. Plagioclase showed zonal texture in the most parts. Most of the plagioclase and biotite were highly altered to clay minerals (Figure 2F).

\section{DIAGNOSIS OF DETERIORATION AND WEATHERING}

\subsection{Mechanical weathering and damage}

The biggest problem of the pagoda from the perspective of weathering damage is the rock strength of each story roof stone and the stylobate, which have suffered from exfoliation and peel-off (Figure 2C). The damage was relatively serious with the materials in the southeast part of the pagoda, where the effects of rainwater, sun light and seawater are mists expected to be stronger. Since, it appeared that no conservation treatments would be effective given at present, many parts needed to be reinforce with the materials of the same petrological features. Representative mechanical damage and weathering effects include broken pieces, cracks and separations. Figure $2 \mathrm{G}$ shows the edge of one roof stone whose square pieces separated, and had concrete filled in, while Figure $2 \mathrm{H}$ features the parts that were missing in the roof stone and pedestal. Regardless of the locations, the gaps between the body, roof stones and the edges of the stylobate heavily destroyed.

The iron wire connecting the gaps of the roof stone also exposed with the parts whose surface pieces peeled off, and where the cement mortar treatments had given (Figure 2H). We can see the
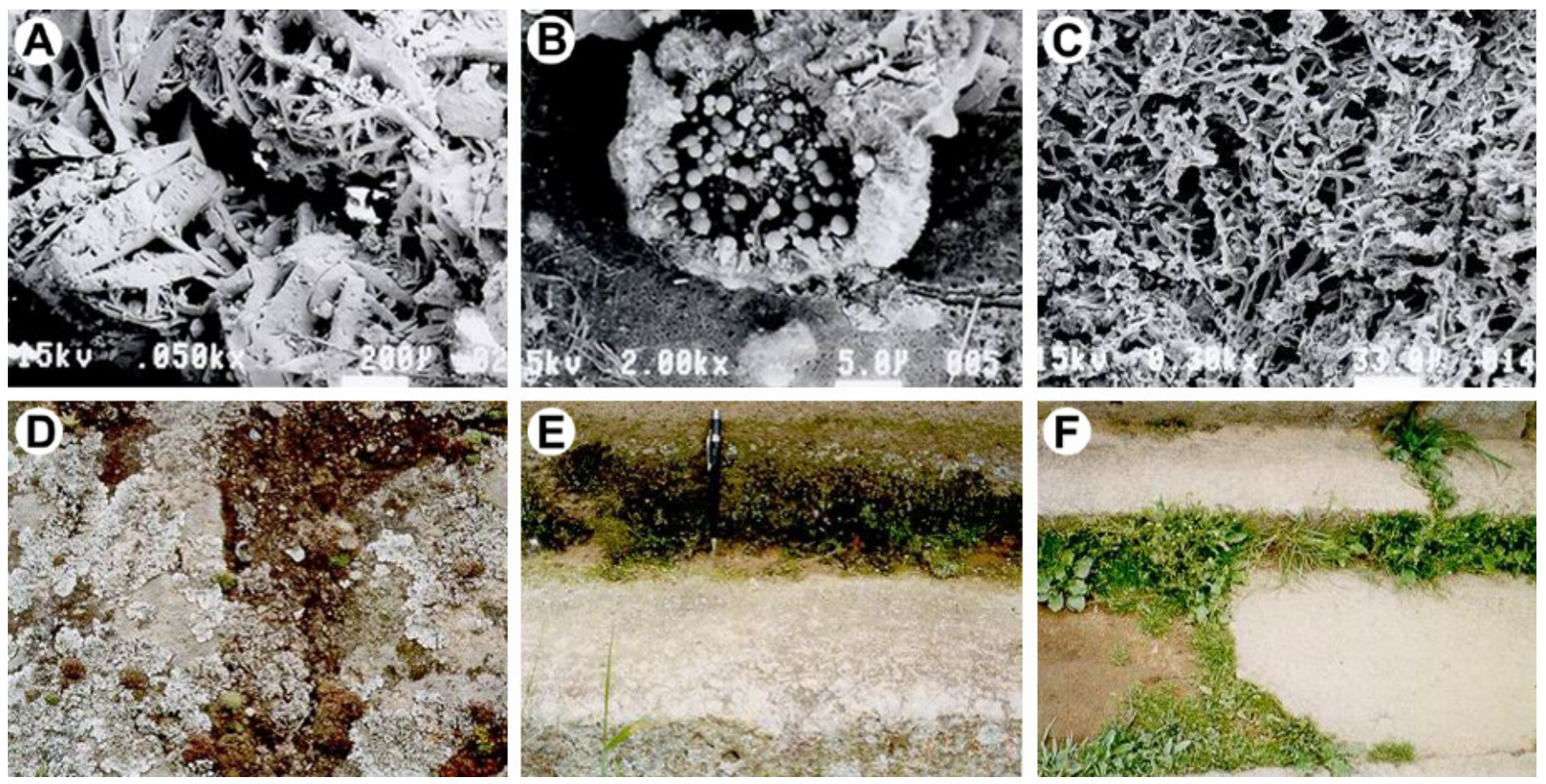

Figure 4. Scanning electron microphotographs (SEM) of clay minerals and biological deteriorations on the surface showing the stone pagoda. (A) Secondary bladed gypsums show light gray precipitates under the roof stone. (B) Kaolinite and smectite aggregate occurred with the near surface weathered roof rocks. (C) Rootlets of lichen and algae grown into the roof rock. (D) Light grey leafy lichen grows from the roof rocks. (E) Black bryophytes coated rocks between the basement and ground rocks. (F) Weeds grow out naturally between ground and basement rocks. 
Table 1. Summary of ultrasonic measurements for each direction host rocks of the West Pagoda.

\begin{tabular}{cccc}
\hline Location & Ultrasonic velocity $(\mathrm{m} / \mathrm{s})$ & Weathering coefficient $(\mathrm{K})$ & Weathering grade* $^{*}$ \\
\hline Lower base rock & $2,172(1,675 \sim 2,624)$ & $0.57(0.48 \sim 0.67)$ & $\mathrm{HW}(\mathrm{HW} \sim \mathrm{CW})$ \\
Upper base rock & $2,267(1,676 \sim 2,819)$ & $0.55(0.44 \sim 0.66)$ & $\mathrm{HW}(\mathrm{HW} \sim \mathrm{CW})$ \\
1st body rock & $2,103(1,763 \sim 2,457)$ & $0.58(0.51 \sim 0.65)$ & $\mathrm{HW}(\mathrm{HW} \sim \mathrm{CW})$ \\
1st roof rock & $2,147(1,455 \sim 2,991)$ & $0.57(0.40 \sim 0.71)$ & $\mathrm{HW}(\mathrm{HW} \sim \mathrm{CW})$ \\
2nd body rock & $2,586(1,698 \sim 2,971)$ & $0.48(0.41 \sim 0.66)$ & $\mathrm{HW}(\mathrm{HW} \sim \mathrm{CW})$ \\
2nd roof rock & $2,205(1,774 \sim 2,575)$ & $0.56(0.49 \sim 0.65)$ & $\mathrm{HW}(\mathrm{HW} \sim \mathrm{CW})$ \\
3rd body rock & $1,373(1,206 \sim 1,552)$ & $0.73(0.69 \sim 0.76)$ & $\mathrm{CW}(\mathrm{CW} \sim \mathrm{CW})$ \\
3rd roof rock & $1,783(1,281 \sim 2,667)$ & $0.64(0.47 \sim 0.74)$ & $\mathrm{CW}(\mathrm{HW} \sim \mathrm{CW})$ \\
\hline Average & 2,174 & 0.57 & $\mathrm{HW}$ \\
\hline
\end{tabular}

*Weathering grade (Iliev, 1966); Highly weathered (HW), Completely weathered (CW).

reddish brown precipitates in those parts. The materials consisting of the pagoda body were scattered with small and big cavities, most of which took the place of basic xenolith. Those materials had the deep grooves, and some of the roof stones had perfect holes here and there (Figure 2I). Some of the original parts still left proving that they were basic xenolith. Rounded holes about $5 \mathrm{~cm}$ in diameter were lying here and there in the stylobate and foundation stones, which were the product of artificial damage by the local people and tourists. The open holes had exfoliation and rugged surface too.

Based on the detail survey results, a deterioration maps in elevations drawn for each side of the pagoda, and its damage was presentation. The ones from the first and second-floor showed the traces of lost pieces and cavities. The third roof stones were severely damaged by exfoliation and peel off due to iron plates, concretes and cement exposed in the wide gaps. Overall, the rocks were damaged so much that any repairs would not do the work. The only left option was replacement. As shown in Figure 3, there is a preliminary assessment for damage degree of the pagoda.

\subsection{Geochemical and mineralogical damages}

Geochemical and mineralogical weathering of the rocks was done by a combination of many different factor, and destroy its composition and texture. Using the behavioral characteristics, enrichments and deficiency of elements due to weathering, the chemical index of alteration (CIA) and weathering potential index (WPI) were calculated (Nesbitt and Young, 1982; 1984). In general, CIA represents the changes to the alkali elements against immobile $\mathrm{Al}_{2} \mathrm{O}_{3}$. The higher index is the stronger weathering degree. The WPI starts at 0 , and high WPIs indicate great sensitivity to chemical weathering. The pagoda materials had the CIA and WPI from 50.36 to 52.03 and 0.34 to 5.58 , being almost homogeneous and little higher-

Under the polarizing microscope, most feldspar altered into sericite and kaolinite. The biotite was also replacement with chlorite, epidote and iron hydroxides along the grain boundaries and cleavages. The observation of the scanning electron microscope (SEM) revealed that feldspars had developed many cavities because of corrosion. In particular, we could see the bladed shaped crystals of gypsum and calcite (Figure 4A). There were light grey precipitates from the dissolved cement mortar. In addition, there were smectite and zeolite minerals of diverse crystal types produced secondary in the cavities and intergranular space of the rock-forming minerals (Figure 4B). Finally, there were kaolinite, lichens, algae roots and mycelium on the boundaries of feldspar where those organisms got tangled with each other (Figure 4C).

\subsection{Biological weathering}

Once microorganisms attach to the rock surface, the biofilm starts to attract diverse algae and the spores of lower plants, which in turn increase the water keeping capacity of the surface and help to provide enough water for the growing lower plants. Then, lichens appear, which are followed by the attack of bryophytes and tree roots (Lisci et al., 2003; Young and Urquhart, 1998). In general, the root of biospecies imposes pressure to the rock surface, and secretes extreme acid substances at the end, causing strong chemical weathering to occur on the rock. In addition, the respiration and evaporation of the plant play a critical role in chemical weathering (Billings, 1950).

The stone pagoda was seriously contaminated with fungi, algae and lichens living on the surface and showed yellowish brown, greenish blue or dark green spots. Once they stop growing, they will turn pitch dark to gray brown, and disturb the entire look of the pagoda and accelerate weathering as well. The lichens covered about $70 \%$ of the stone surface. However, about $90 \%$ of the roof stones were taken over by them suffering from serious organisms living on them (Figure 4C). There were mosses and brackens 
living where the sun light did not reach, and the relative humidity was rather high (Figure 4D). Thus, it is necessary to risk artificial weathering when they tried to remove the organisms from the stone surfaces. Furthermore, the weeds seriously contaminated
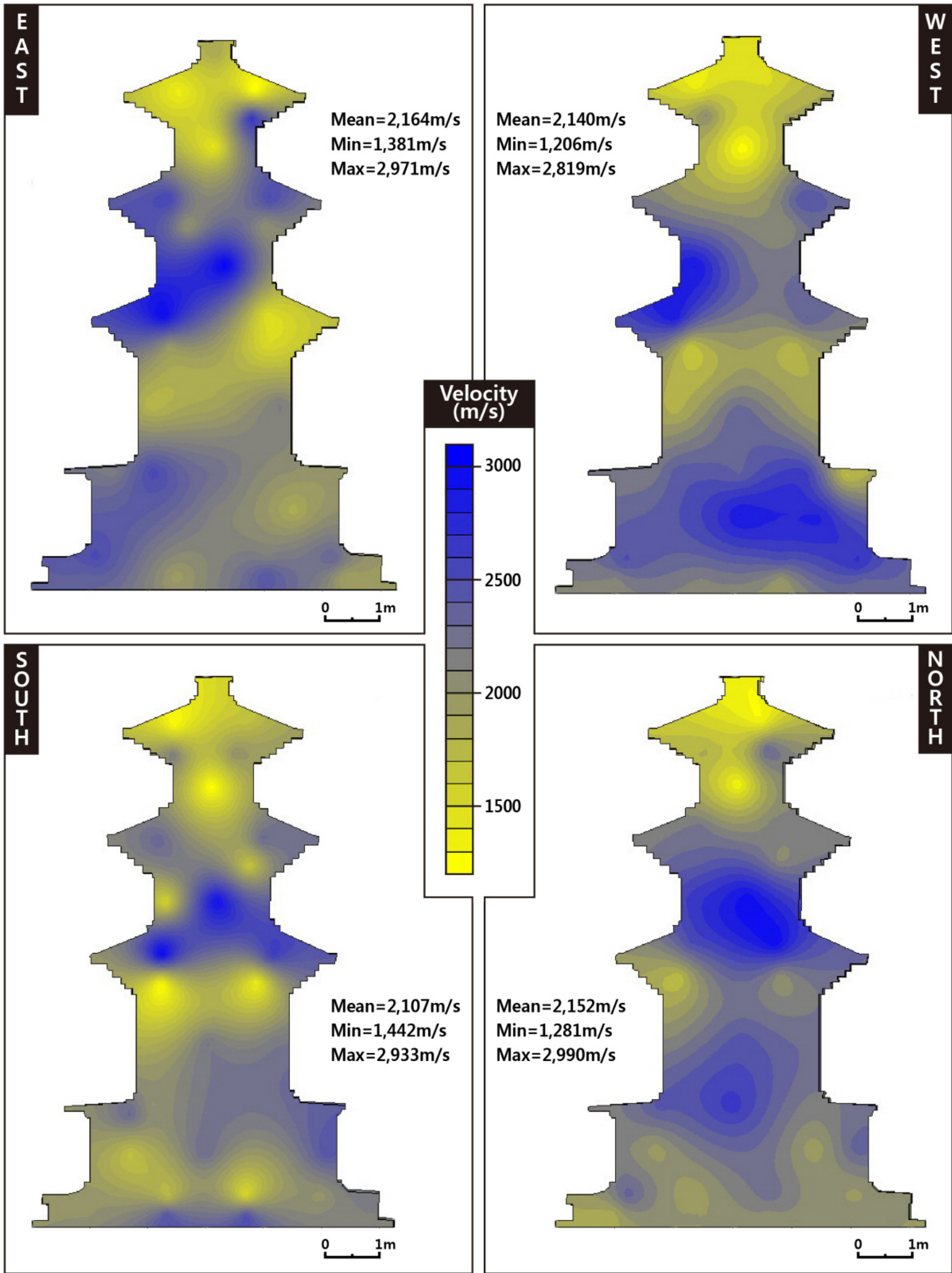

Figure 5. Contour 2D modeling maps by projecting the ultrasonic velocity of stone pagoda. 
to the stylobate (Figure 4E, 4F). It is urgent to take some measures since those diverse organisms in all are accelerating mechanical weathering.

Figure $4 \mathrm{C}$ is scanning electron micrographs of the organisms from the near surface of the roof rocks. Even the samples that were collected $2 \mathrm{~cm}$ deep from the surface of the roof stones had the tangled up spores of lichens and hypha (Crustose lichen's rhizoid) of about $3 \mu \mathrm{m}$ in thickness in the cavities of the rock-forming minerals. In combination with the clay minerals that were produced secondary, the spores of the lichens and hypha in the intergranular gaps of quartz and feldspar filled up the other intergranular space of the rock-forming minerals. The biological weathering was thus in a variety of types. Those rocks easily taken away in pieces with a small shock since exfoliation and mineralogical weathering proceeded to the serious point.

\subsection{Ultrasonic measurements}

Ultrasonic measurement was carried out for the pagoda to evaluate quantitative weathering degree, and the measurement was applied for 93 points on the rock surface by indirect method with 20 centimeter in distance. Table 2 shows ultrasonic velocity of the rocks, and weathering index and grade was calculated by Iliev (1966).

The ultrasonic velocity ranged from 1,206 to $2,991 \mathrm{~m} / \mathrm{s}$, and the average value was $2,174 \mathrm{~m} / \mathrm{s}$. Weathering index was distributed in the ranged from 0.41 to 0.76 (average 0.57 ) that indicated Highly Weathered Degree (Table 1). The $3^{\text {rd }}$ body and roof stones were evaluated as the most weathered rocks that weathering index was 0.73 . Most rock blocks fell under Highly Weathered Grade (HW), and the southern parts of the pagoda, especially, included the most blocks evaluated as Completely Weathered Grade (CW).

The ultrasonic velocity values were projected to a map of the pagoda to understand velocity distribution (Figure 5). The contour map showed generally higher weathering degree of roof top parts than ones underneath the roof. According to elevation, the velocity was gradually decreased from the basement to the top. It was inferred that the gradual difference in weathering degree of the pagoda stones was brought out from differential intensity of exposure to outdoor climate. Thus, a protective facility could be concerned to slow down further weathering by environmental exposure.

\section{DISCUSSION AND CONCLUSIONS}

Climatically, the Korean Peninsula shows four distinct seasons with moderately hot summers and cold winters. In winter, winds commonly originate from the northeast resulting in a wide range of typical temperatures of northern continental conditions. In summer, winds commonly come from southeast resulting in high temperatures and humidity. Temperatures recorded over 84-year (1923 to 2006) show a typical cyclic variation between about -15 and $35^{\circ} \mathrm{C}$ with an annual mean temperature of about $18^{\circ} \mathrm{C}$. The 84 -year mean annual precipitation amount is about $1,300 \mathrm{~mm}$. However, rainfall varies considerably from place to place. High temperatures and humidity from the northern Pacific air mass usually results in a monsoonal rainy season lasting from June to September. This period amounts for $68 \%$ of the total annual rainfall (KMS, 2007).

Since, the stone pagoda has long been in reaction with rainwater, moisture in the air and seawater mists, its surface weathering cannot be worse. To make things worse, the host rocks contain basic xenolith, which is prone to weathering. The rough surfaces of the materials are the decomposition of mafic minerals and feldspar. Siliceous acid from the water-rock reactions provide nutrients in plants, while the damaged area on the stone offers a home to the plants. During winter, a repeated freezing and melting of water gives a mechanical damage to the rocks. The crystallization of seawater mists coming from the coast is another problem. The soil around the pagoda has expanded the territory up to the stylobate and helps to residues of evaporation form in precipitates. Deterioration of the pagoda has reached the ultimate state of the materials in southeast parts where the attacks of sea winds, rainwater and sun light are very active. To prevent them, it is reasonable to consider waterproof treatment for the material surfaces.

Weathering of the pagoda is the result of many factors operating in complex ways. Mostly southeastern stylobate decreased in rock strength due to exfoliation and peel off with the weathering damages, thus seems to have difficulties with supporting the materials above. Its relatively serious damage is due to fact that it exposed to the meteorological impacts. In the moments, no conservation treatments will have any effect, which calls for the use of fillers, hardeners and surface treatment substances designed to preserve cultural assets or the decision whether materials of the same kind as them in the petrological aspect should be adopt.

There were our research articles including the evaluation for weathering damages and conservation treatments of some stone cultural heritages (Lee et al., 2003; 2005). In the future, we should be conducting the monitoring for damage processes, and how to establish and carry out long-term plans. For the rocks of the body that can cause a problem to the support as they are severely damaged, a consideration should be made on how to replace them and how to reinforce them in the engineering respect. In addition, the removing methods of the organisms on the stone surface should be examination. For a conservational treatment of a stone culture heritage, they usually use repair glues including fillers and water repellent hardeners so as not to damage the appearance. There are some reports on the application cases and problems (Lee et al., 2006). It is important to investigate the weathering causes 
and corrosion mechanism, and conduct a clinical test before choosing and applying some chemicals to preserve stone cultural heritages.

\section{REFERENCES}

Ashurst, J. and Dimes F.D., 2001, Conservation of building and decorative stone. Butterworth and Heinemann, Oxford, p.254.

Billings, W.D., 1950, Vegetation and plant growth as affected by chemically altered rocks in the Western Great Basin. Ecology, 31, 62-74.

CHA (Cultural Heritage Administration), 2012, Detail information of cultural properties in Korea. http://www.cha.go.kr.

Fidler, J., 2002, Stone building, construction and associated component system: their decay and treatment. English Heritage Research Transactions, 2, p.1-104.

Fitzner, B., 2004, Documentation and evaluation of stone damage on monuments. In: Proceedings of the 10th international congress on deterioration and conservation of stone, Stockholm, Sweden, p.677-690.

Iliev, I.G., 1966, An attempt to measure the degree of weathering of intrusive rocks from their physico-mechanical properties. In: Proceedings of the 1st congress of the international society of rock mechanics, Lisbon, Portugal, 1, p.109-114.

Jeong, Y.H., Son, J.S. and Ahn, J.H., 1999, Stone Pagoda in Korea. Daewonsa Publishing Company, Seoul, Korea, p.130.

Jwa, Y.J., Lee, S.W., Kim, J.S. and Sohn, D.W., 2001, Source area of stone used for the stone building of Bulguksa temple and Seokguram grotto. Journal of Geological Society of Korea, 36, 335-340.

KMS (Korea Meteorological Serivce), 2007, Climatic summary of Korea. http://www.kma.go.kr.

Lee, C.H., Choi, S.W. and Suh, M., 2003, Natural deterioration and conservation treatment for the granite standing Buddha of Daejosa tem- ple, Republic of Korea. Geotechnical and Geological Engineering, 21, 63-77.

Lee, C.H., Jo, Y.H. and Kim, J., 2011, Damage evaluation and conservation treatment of the 10th century Korean rock-carved Buddha statues. Environmental Earth Science, 64, 1-14.

Lee, C.H., Lee, M.S., Kim, Y.T. and Kim, J., 2006, Deterioration assessment and conservation of heavily degraded Korean stone Buddha from the ninth century. Studies in Conservation, 51, 305-316.

Lee, C.H., Lee, M.S., Suh, M. and Choi, S.W., 2005, Weathering and deterioration of rock properties of the Dabotap pagoda (World Cultural Heritage), Republic of Korea. Environmental Geology, 47, 547-557.

Lee, C.H., Lee, M.S., Suh, M., Choi, S.W. and Kim, M.G., 2004, Deterioration diagnosis and source area of rock properties at the West Stone Pagoda, Gameunsaji Temple Site, Korea. Economic and Environmental Geology, 37, 569-583.

Lee, M.J., Lee, J.I. and Lee, M.S., 1995, Mineralogy and major element geochemistry of A-type alkali granite in the Gyeongju area, Korea. Journal of the Geological Society of Korea, 31, 583-607.

Lisci, M., Monte, M. and Pacini, E., 2003, Lichens and higher plants on stone: a review. International Biodeterioration and Biodegradation, 51, 1-17.

Nesbitt, H.W. and Young, G.M., 1982, Early Proterozoic climates and plate motions inferred from major element chemistry of lutites. Nature, 299, 715-717.

Nesbitt, H.W. and Young, G.M., 1984, Prediction of some weathering trends of plutonic and volcanic rocks based on thermodynamic and kinetic considerations. Geochemica et Cosmochemica Acta, 48, 1523-1534.

Young, M.E. and Urquhart, D.C.M., 1998, Algal growth on building sandstone: effects of chemical stone cleaning methods. Quarterly Journal of Engineering Geology, 31, 315-324. 